not infrequently bring about, that their large size is not detrimental except in so far as it limits their number.

The seeds of many members of the marrow family are of only moderate size, but the fruits in which they are contained are among the most diverse in size and form, and some attain large dimensions even in the wild state. They are dispersed by flotation, and after the fruits cease to be buoyant the seeds will often float for weeks.

Unless the dispersal of fruits or seeds be reasonably efficient, it is manifest that no advantage will accrue from a large output and little from a large food supply, and the great diversity of so-called dispersal mechanisms is evidence of their considerable survival value; but beyond a certain efficiency the higher the output consistent with adequate reserves in the seed for establishment, the greater the frequency of the species is likely to be.

It is worth noting that man, in the cultivation of his fruits, has often selected out seedless types. Sometimes this is the outcome of hybridization and resultant genetic infertility; sometimes it is the accompaniment of the mere replication of chromosomes. The seedless banana, the seedless orange and the pineapple are familiar examples of such fruits, which emphasize for us that fruit formation and seed production, though commonly associated phenomena, may be independent of one another. We can indeed, by the use of artificial growth-promoters, cause pears to develop which contain no fertile seeds. In the wild state we find that chromosome replication is not infrequently accompanied by a reduction in fertility but an augmentation of vegetative propagation. Thus, many woodland species that have low seed outputs spread rapidly by runners, of which a striking example is afforded by the lesser periwinkle (Vinca minor), which flowers freely but very rarely fruits, yet spreads with remarkable rapidity. The vegetative mode of propagation has many advantages in a shady habitat.

All the evidence we at present possess would appear to lead to the conclusion that seed output is an important factor in successful colonization, and its magnitude is as much a character of the species as height or any other of its variable qualities.

\title{
OBITUARY
}

\section{Prof. P. A. Buxton, C.M.G., F.R.S.}

The news of the death of Prof. P. A. Buxton on December 13 at his home, Grit Howe, Gerrards Cross, shocked and sorrowed his friends and admirers in all parts of the world. Only a year previously he was travelling through difficult forest. country in Central America, a few months ago he was still castigating committees with his caustic wit, and right up to the end he was giving that critical help to his colleagues and students for which they will never find a substitute.

Buxton was born on March 24, 1892. He read the Natural Sciences Tripos at Trinity College, Cambridge, and received his medical education at St. George's Hospital. He became acquainted with tropical conditions first during the First World War in Iraq and Iran, then for two years in Palestine and later for two years in the Pacific Islands. In 1926 he became director of the Department of Entomology of the London School of Hygiene and Tropical Medicine, and in 1933 professor of medical entomology of the University of London, appointments which he held until his death. He was elected a Fellow of the Royal Society in 1943, was made C.M.G. in 1947, received the Mary Kingsley Medal of the Liverpool School of Tropical Medicine in 1949 and was awarded the Linnean Gold Medal in 1953.

Buxton altered the course of medical entomology from museum systematics to the study of the living insect, its physiology and its relationship to the environment. His highly original mind was drawn to this practically unexplored field, and a series of classical papers followed. From these observations he was able to synthesize the findings in five books, characterized by the most lucid exposition of the subject. The first, "Animal Life in Deserts", was reprinted in 1955, and is in constant use by a circle of workers much wider than entomologists. Then after his visit to the Pacific appeared three volumes dealing with medical conditions and entomology in Samoa and other islands. His book on the louse went into two editions and is a perfect example of his outlook. Finally, two works on trypanosomiasis and the tsetse fly appeared, first a preliminary memoir and then, just before his death, the compre. hensive "Natural History of the Tsetse Flies", a book which all workers in Africa have been awaiting for years.

Buxton's creed may be summed up in his own words : "field observations are a necessary preliminary, but their function is to set problems which should be solved in the laboratory". He communicated this point of view to some carefully chosen students, all of whom have attained positions of eminence in this field; he thus founded a school of thought which has the strongest influence wherever entomology is studied. Buxton's own journeys helped this dissemination, for not only was he widely travelled but also foreigners found him sympathique.

The part that Buxton played in introducing the synthetic insecticides into medicine is perhaps not fully recognized. Early in 1943, the insecticide DDT was brought to him from Switzerland, where it had recently been resynthesized; he immediately appreciated its significance, and he was largely responsible for its rapid introduction as an insect killer in the various theatres of the Second World War.

Buxton's advice was sought more and more frequently by committees or councils at home and abroad, and much of his time latterly was occupied in this way ; he never really liked this diversion from his research and teaching, but felt that it was his duty as a scientist to give advice to official bodies; and they always got it in forthright terms. He was due for 'retirement' in two years time, and he had already acquired a subject which would have kept him busy for years; he had started studying the breeding of Diptera in fungi, and only twelve months before his death he bought a binocular microscope with which to observe these flies at his house in Gerrards Cross. Many people all over the world will remember his garden there, its interesting plants and trees, and above all, the welcome they received.

P. C. C. Garnham 